\title{
Biological features and economically valuable characteristics of apple varieties (Malus domestica Borkh.)
}

\author{
Olga Merezhko, Evgenia Aminova*, Rufina Salimova \\ Orenburg branch of the Federal State Budgetary Scientific Institution FNTs Gardening, 10 Nezhinskoe highway, \\ Orenburg, 460041, Russia,
}

\begin{abstract}
The purpose of the research is to create winter-hardy, large-fruited, high-yielding, high-quality varieties of apple trees of different ripening periods and their growing technology (use of a biological product) in the South Urals. The research was carried out on the basis of Orenburg a branch of the Federal State Budgetary Scientific Institution "Federal Scientific Selection and Technology Center for Horticulture and Nursery" from 1999 to 2020. Research objects were summer apple varieties - Orenburgskoe, Orenburgskoe krasnoe, Letnee polosatoe (K); winter - Orenburgskoe pozdnee, Zimnee, YUzhnoural'skoe $(\mathrm{K})$. The counts and observations were carried out according to generally accepted methods. As a result of the studies, the data obtained showed that the property of short stature as a genetic trait of resistance is transmitted to the offspring during hybridization. The varieties Orenburgskoe pozdnee, Zimnee and YUzhnoural'skoe showed the greatest increase in productivity embodiment experience "Evrikor - Forte + 7" $2.51 /$ ha by $25.4 \%, 24.3 \%$ and $22.2 \%$ respectively. Thus, the application of "Evrikor - Forte + 7" increased both the number of fruits and their weight, and also increased the yield of the studied varieties.
\end{abstract}

\section{Introduction}

In recent years in many countries, including Russia, interest in gardening has been increasing, one of the links of which is the use of low-growing forms of trees with a compact crown and the usual non-sporous type of fruiting. The steppe zone of the South Urals belongs to the arid zone and is characterized by atmospheric drought and low precipitation.

At the same time in the conditions of the Urals, one of the most important advantages of the apple tree is its high winter hardiness. The possibility of growing apple trees as a crop in our region appeared after the creation of a winter-hardy assortment. However, in the created varieties, in some severe winters, significant damage to the wood was noted, fruit buds often froze. Therefore, for our zone, we can consider the positive effect of snow for undersized varieties. We are faced with the task of identifying winter-hardy, drought-resistant, fruitful varieties of pome crops [1,2]. Along with grafting on low-growing vegetatively propagated rootstocks to obtain such plantings, it is of great interest to use lowgrowing varieties that maintain a restrained tree growth when grafted onto ordinary seed stocks.

In a scientific article, Sedov (2015) points out that only 140 cultivars from the RSRISH apple gene pool were used in breeding as initial forms both in Russia and abroad, and are the ancestors of new cultivars [3]. The correct selection of the original parental forms contributes greatly to the success of breeding new varieties. However, it is important to breed special lowgrowing varieties with a flat-horizontal crown. When introducing such varieties, it is very important to select the initial parental varieties for crossing with short stature characters. It should be noted that among woody plants there are undersized weeping forms in cedar, mulberry, mountain ash, ash and other species apple tree $[4,5]$. The weeping crown shape in apple tree is determined by a separate gene or several genotypes, as well as the nature of the recently revealed compact crowns [6].

In recent years the cultivation of orchards, obtaining an environmentally friendly and stable harvest has taken one of the main places in the fruit growing industry of the South Urals. At the same time in modern agriculture, along with fungicides, herbicides and insecticides, various biological products are also used [7]. To obtain biologically valuable products and preserve soil fertility it is necessary to use biological products in plant growing that improve plant root nutrition, increase resistance to stress factors, stimulate plant growth, the formation of ovaries and fruits, accelerate ripening times, and improve product quality. Biologics are safe for the environment and promote sustainable low-cost crop production $[8,9]$.

\section{Problem Statement}

For an arid climate, it is necessary to create winterhardy, large-fruited, high-yielding, high-quality apple varieties of different ripening periods and to improve the elements of their cultivation technology (use of a biological product). 


\section{Research Questions}

Research was carried out at the Orenburg a branch of the Federal State Budgetary Scientific Institution "Federal Scientific Selection and Technology Center for Horticulture and Nursery" from 1999 to 2020. Research objects are summer apple varieties Orenburgskoe, Orenburgskoe krasnoe, Letnee polosatoe $(\mathrm{K})$; winter apple varieties - Orenburgskoe pozdnee, Zimnee, YUzhnoural'skoe (K); organic-mineral humic fertilizer "Evrikor - Forte + 7" (composition: $\mathrm{N}-8.4 \%, \mathrm{P}-3.6 \%$, $\mathrm{K}-10.4 \%, \mathrm{~B}-0.7 \%, \mathrm{~S}-0.04 \%, \mathrm{Fe}-0.06 \%, \mathrm{Cu}-0.01 \%$, $\mathrm{Zn}-0.01 \%$, Co $-0.0005 \%$, Mo-0.0012\%. Li, Cr, Ni - in chelate form).

\section{Purpose of the Study}

The object of study is Orenburgskoe pozdnee (was obtained from crossing of Vydubetskaya weeping with Welsey). The authors are M.A. Mazunin, N.F. Mazunina, O.E. Merezhko.

The tree is a natural dwarf, the crown is of medium density, rounded-spreading, branches are crooked, rarely located. The leaves are dark-green; the edge of the leaf is finely crenate. The flowers are pinkish, with oval petals. Fruits weighing 140-160 g are large up to $320 \mathrm{~g}$ of round conical in shape. The skin is soft, smooth, greenishyellow; most of the fruit is dark red. The peduncle is of medium size and straight. The funnel is medium and blunt-conical. The cup is half-open, the saucer is medium (Fig. 1).

The main color when removed and at full maturity is greenish-yellow. The cover color on most of the fruit surface is dark red. Seeds are ovoid, brown. The pulp is creamy, medium density, fine-grained, juicy, sweet and sour taste, with a medium aroma. Removable ripeness occurs in the third decade of September. Duration of storage of fruits is up to 170 days. Productivity is 146.5 $\mathrm{kg} / \mathrm{ha}$. The variety has high winter hardiness and is resistant to scab.

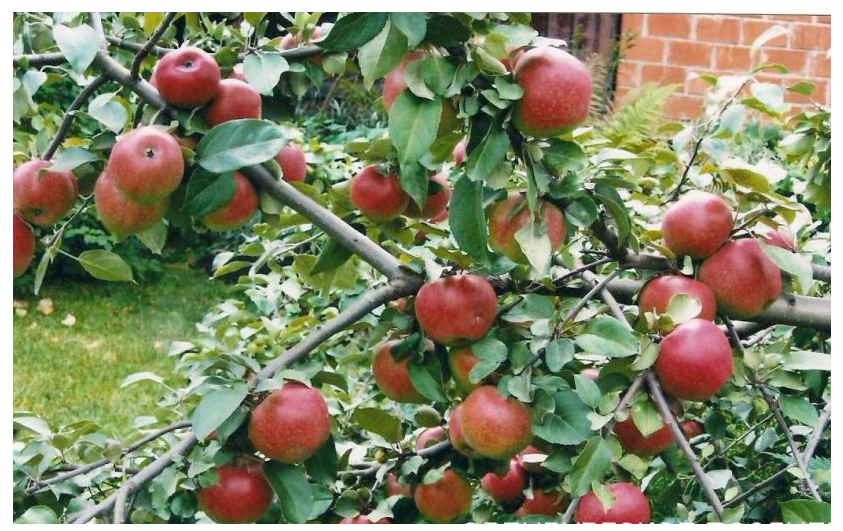

Figure 01. Apple variety "Orenburgskoe pozdnee"

Winter variety of selection (was obtained from crossing of Vydubetskaya weeping with YUzhnoural'skoe). The authors are M.A. Mazunin, N.F. Mazunina, O.E. Merezhko.
The tree is a natural dwarf, the crown is of medium density, the branches are crooked, located rarely; the ends of the branches are directed upwards. Shoots are brown, medium, arched. The buds are medium. Leaves are medium, oblong, elliptical, green, corrugated with gentle nerves. The leaf blade is concave and curved downward. The leaf edge is finely serrate and wavy. The flowers are chalky, pink with aroma. The petals are round, medium. Fruits weighing $120 \mathrm{~g}$ are large up to $190 \mathrm{~g}$, flattened-spherical, slightly ribbed. The skin is soft, smooth, oily, greenish-yellow (Fig. 2).

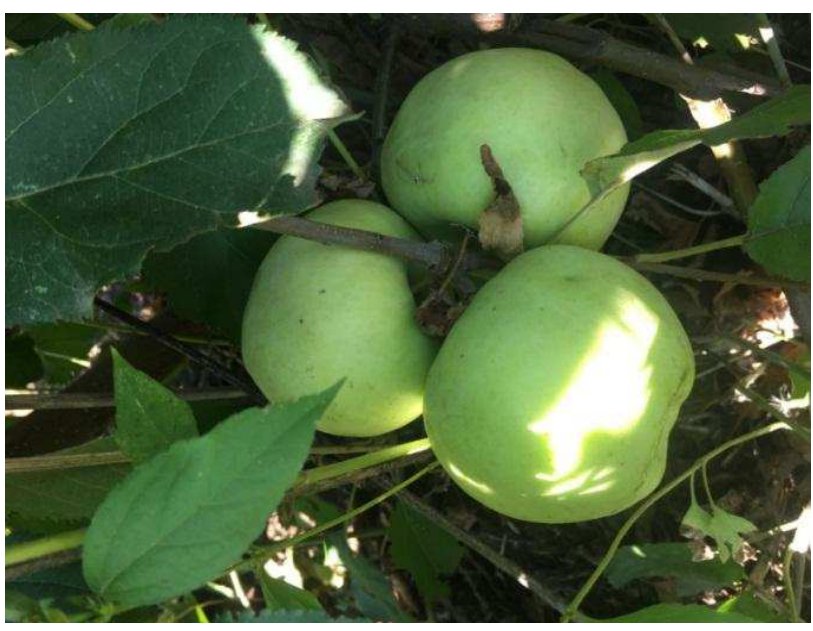

Figure 02. Apple variety "Zimnee”

The main color when removed and at full maturity is greenish-yellow. The integumentary coat is blurred, orange. The subcutaneous points are medium, hardly noticeable. The heart is medium in size, onion. The chambers are semi-open. The pulp is greenish, medium density, tender, fine-grained, juicy, sweet and sour taste, with a medium aroma. Removable ripeness of fruits occurs in the third decade of September. Duration of storage of fruits is up to 100 days. The yield is $162.7 \mathrm{~kg} /$ ha. It has high winter hardiness; the variety is resistant to scab.

Orenburgskoe is a late summer variety It was obtained from crossing a seedling of a large-fruited apple tree 8-95 with White filling. It is distributed and zoned in the Ural region. The authors are M.A. Mazunin, N.F. Mazunin, O.E. Fatneva.

The tree is a natural dwarf, the crown is of medium density, branches are rare. The bark on the trunk and main branches is peeling and gray. Fruiting is at the ends of the growth shoots (Fig. 3). Shoots are medium, round, pubescent, green in color. Fruits are large, onedimensional, rounded, slightly ribbed. The peduncle is medium and curved. The funnel is medium, bluntconical, the calyx is half-open; the saucer is medium, wide. The skin is medium, oily.

The main color at the time of ripening is whitishyellow. The integumentary over the least part of the fetus is red, the subcutaneous dots are medium green. 


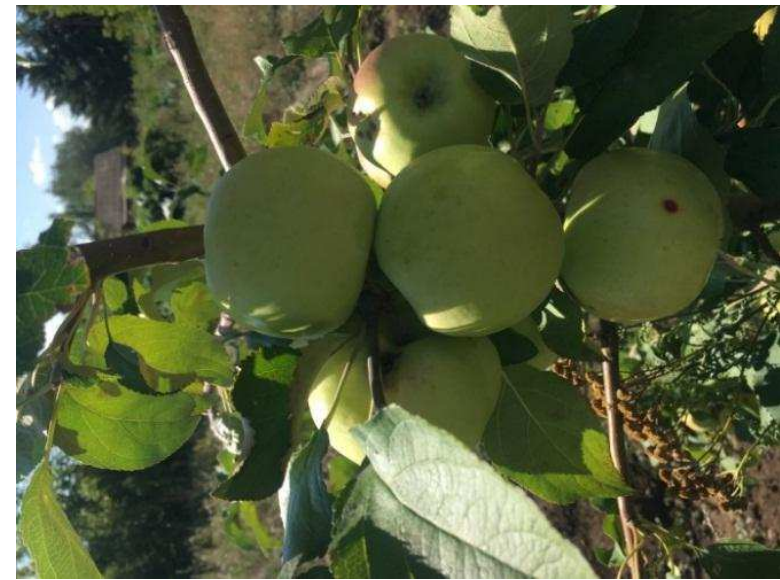

Figure 03. Apple variety "Orenburgskoe"

Removable ripeness of fruits occurs in the first decade of September. The duration of storage of fruits is up to 40 days. The productivity is $193.3 \mathrm{~kg} / \mathrm{ha}$. The winter hardiness is high; the variety is resistant to scab.

Orenburgskoe krasnoe - a summer variety was obtained from free pollination and distributed in the Ural region. The authors are E.Z. Savin, O.E. Merezhko, G.R. Mursalimov.

The tree is medium-sized; the shape of the crown is spreading; branches are rare. The bark on the trunk and main branches is smooth, reddish in color (Fig. 4).

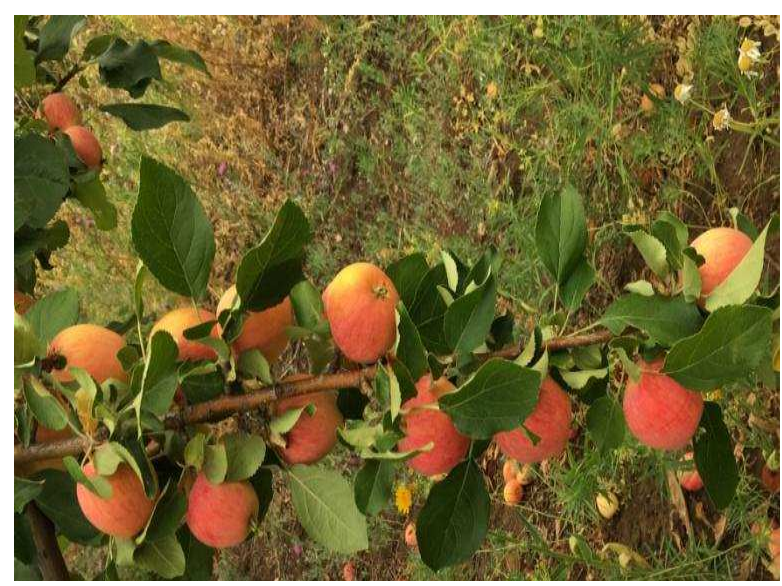

Figure 04. Apple variety "Orenburgskoe krasnoe"

Shoots are medium, straight, pubescent, brown. The buds are medium, pressed, pubescent, rounded. The leaves are matte, dark green with a bluish tint. The flowers are small, chalky, pinkish, fragrant. The petals are medium, oval. Fruits weighing is $120 \mathrm{~g}$; they are onedimensional, round. The stalk is medium, straight. The funnel is shallow, blunt-conical, rusty, weak; the calyx is half-open, the saucer is medium, smooth. The skin is soft, smooth, shiny. The main color is greenish at the time of ripening. The cover paint throughout the fruit is blurry, dark red in color. Subcutaneous points are small, hardly noticeable. The heart is medium, cordate. The pulp is creamy, medium density, tender, juicy, sweet and sour taste, with a medium aroma. Removable ripeness occurs in the August. The productivity is $170.0 \mathrm{~kg} / \mathrm{ha}$. The variety has high winter hardiness; the variety is resistant to scab.

\section{Research Methods}

Here let us consider the experiment design and terms of treatments and method of application. Foliar feeding of plants is as follows. The 1st is in the "pink bud" phase, the 2 nd is after flowering, the $3 \mathrm{rd}$ is after the formation of the ovary. The consumption of the working solution is $8001 /$ ha. The planting scheme is $3 \times 5 \mathrm{~m}$, 4-fold repetition, the area of the experimental plots is $1800 \mathrm{~m}^{2}$, the number of experimental plants is 5 pcs.

Soluble solids were determined by the refractometric method in accordance with GOST ISO 2173-2013, titratable acidity in accordance with GOST Z 514 34-99. The sugar-acid index was calculated. Ascorbic acid was determined titrimetrically. All results are calculated on the basis of analyses carried out in four replicates $(\mathrm{n}=$ 4). Field experiments, records, observations were carried out according to generally accepted methods [10 - 12]. Statistical analysis was performed using the office software package "Microsoft Office" using the program "Excel" ("Microsoft Office", USA).

\section{Findings}

In the course of the study, a comparative analysis of the winter apple varieties Orenburgskoe pozdnee, Zimnee, YUzhnoural'skoe $(\mathrm{K})$ was carried out in terms of the average fruit weight, average yield and biochemical analysis. The bred apple varieties in comparison with the control by weight exceed by $56.0 \mathrm{~g}$ (Orenburgskoe pozdnee), $26.0 \mathrm{~g}$ (Zimnee). The average yield of the Orenburgskoe pozdnee variety exceeds the control by $10.4 \%$, and the Zimnee variety - by $32.6 \%$ (Table 1). In summer apple varieties Orenburgskoe and Orenburgskoe krasnoe, the excess of control in terms of fruit weight was $30.0 \mathrm{~g}$ and $40.0 \mathrm{~g}$, respectively. The average yield of the Orenburgskoe variety exceeds the control by $34.9 \%$, the Orenburgskoe krasnoe variety - by $18.6 \%$.

Biological products affect the growth and development of plants and also mitigate the negative effects of environmental stresses in the process of ontogenesis. Treatment with the studied drugs in the first half of the growing season contributed to the strengthening of physiological and biochemical processes in apple trees, that is, there was a good preservation of the economically useful ovary, strong retention, normal growth and development of apple fruits.

The highest percentage of useful ovary in summer varieties Orenburgskoe krasnoe and Orenburgskoe during processing was noted in the variant "Evrikor Forte $+7 "$ (2.5 1/ ha) $-30.4 \%$ and $30.0 \%$, exceeding the control value almost 2 times. And in varieties of winter ripening at the same concentration the indicator of useful ovary was equal to $29.9 \%$ (variety Zimnee), exceeding the variant without treatment 1.9 times. The smallest percentage of useful ovary was noted in the variant with the treatment "Evrikor - Forte + 7" $3.51 /$ ha and exceeded the indices without treatment 1.4 times (Table 2). 
Table 01. Comparative characteristics of apple varieties, 1999-2020

\begin{tabular}{|c|c|c|c|c|c|c|c|}
\hline \multirow[b]{2}{*}{ Variety } & \multirow{2}{*}{$\begin{array}{l}\text { Average } \\
\text { fruit weight, } \\
\mathrm{g}\end{array}$} & \multicolumn{3}{|c|}{ Assessment by chemical composition } & \multicolumn{3}{|c|}{ Average yield } \\
\hline & & $\begin{array}{l}\text { Vitamin } C, \\
\mathrm{mg} / 100 \mathrm{~g}\end{array}$ & Sugar, $\%$ & $\begin{array}{l}\text { Soluble } \\
\text { dry matter, \% }\end{array}$ & Acids, $\%$ & $\mathrm{~kg} / \mathrm{der}$ & c/ ha \\
\hline \multicolumn{8}{|c|}{ Summer varieties of apple trees } \\
\hline Letnee polosatoe $(\mathrm{K})$ & $80.0 \pm 5.6$ & $19.4 \pm 0.4$ & $10.6 \pm 0.2$ & $14.3 \pm 0.1$ & 0.7 & $25.8 \pm 1.1$ & 143.3 \\
\hline Orenburgskoe & $110.0 \pm 7.7$ & $19.4 \pm 0.6$ & $10.6 \pm 0.2$ & $14.3 \pm 0.3$ & 0.7 & $34.8 \pm 2.6$ & 193.3 \\
\hline Orenburgskoe krasnoe & $120.0 \pm 6.2$ & $15.4 \pm 0.4$ & $11.1 \pm 0.3$ & $13.3 \pm 0.3$ & 0.7 & $30.6 \pm 2.3$ & 170.0 \\
\hline $\mathrm{NSR}_{0.5}$ & - & - & - & - & - & - & 1.3 \\
\hline \multicolumn{8}{|c|}{ Winter varieties of apple trees } \\
\hline YUzhnoural'skoe (K) & $94.0 \pm 6.1$ & $13.0 \pm 0.2$ & $9.8 \pm 0.2$ & $13.4 \pm 0.1$ & 0.7 & $23.9 \pm 0.9$ & 131.4 \\
\hline Orenburgskoe pozdnee & $150.0 \pm 8.4$ & $16.1 \pm 0.4$ & $10.2 \pm 0.4$ & $13.8 \pm 0.3$ & 0.8 & $26.4 \pm 1.3$ & 146.5 \\
\hline Zimnee & $120.0 \pm 7.9$ & $14.0 \pm 0.2$ & $10.2 \pm 0.3$ & $13.6 \pm 0.3$ & 0.8 & $31.7 \pm 1.8$ & 162.7 \\
\hline $\mathrm{NSR}_{0.5}$ & - & - & - & - & - & 2.8 & 3.1 \\
\hline
\end{tabular}

Table 02. Influence of the "Evrikor - Forte +7 " biological product on the yield of summer and winter apple varieties, 2018-2020

\begin{tabular}{|c|c|c|c|c|c|c|}
\hline \multirow{2}{*}{ Variety } & \multirow[t]{2}{*}{ Processing option } & \multirow{2}{*}{$\begin{array}{l}\text { Discarded } \\
\text { ovary, } \%\end{array}$} & \multirow{2}{*}{$\begin{array}{l}\text { Useful } \\
\text { ovary, } \%\end{array}$} & \multirow{2}{*}{$\begin{array}{l}\text { Average fruit } \\
\text { weight, g }\end{array}$} & \multicolumn{2}{|c|}{ Average yield } \\
\hline & & & & & $\mathrm{kg} / \mathrm{der}$ & $\mathrm{c} / \mathrm{ha}$ \\
\hline \multirow[t]{4}{*}{ Letnee polosatoe } & Without processing & 85.88 & 14.12 & $80.0 \pm 5.6$ & $25.8 \pm 1.1$ & 143.3 \\
\hline & $\begin{array}{l}\text { "Evrikor - Forte + 7" } \\
1.51 / \text { ha }\end{array}$ & 73.83 & 26.17 & $92.0 \pm 2.6$ & $27.0 \pm 1.0$ & 149.8 \\
\hline & $\begin{array}{l}\text { "Evrikor - Forte + 7" } \\
2.51 / \text { ha }\end{array}$ & 71.75 & 28.25 & $95.0 \pm 5.0$ & $28.1 \pm 1.4$ & 155.9 \\
\hline & $\begin{array}{l}\text { "Evrikor - Forte + 7" } \\
3.51 / \text { ha }\end{array}$ & 79.63 & 20.37 & $89.0 \pm 3.3$ & $26.6 \pm 1.6$ & 147.6 \\
\hline \multirow[t]{4}{*}{ Orenburgskoe } & Without processing & 83.52 & 16.48 & $110.0 \pm 7.7$ & $34.8 \pm 2.6$ & 193.3 \\
\hline & $\begin{array}{l}\text { "Evrikor - Forte + 7" } \\
1.51 / \text { ha }\end{array}$ & 72.38 & 27.62 & $121.0 \pm 2.6$ & $36.9 \pm 2.8$ & 204.8 \\
\hline & $\begin{array}{l}\text { "Evrikor - Forte + 7" } \\
2.51 / \text { ha }\end{array}$ & 70.0 & 30.0 & $129.0 \pm 3.8$ & $39.1 \pm 2.2$ & 217.0 \\
\hline & $\begin{array}{l}\text { "Evrikor - Forte + 7" } \\
3.51 / \text { ha }\end{array}$ & 77.31 & 22.69 & $118.0 \pm 3.1$ & $35.3 \pm 1.3$ & 195.9 \\
\hline \multirow{4}{*}{$\begin{array}{l}\text { Orenburgskoe } \\
\text { krasnoe }\end{array}$} & Without processing & 86.12 & 13.88 & $108.0 \pm 3.2$ & $30.6 \pm 2.3$ & 170.0 \\
\hline & $\begin{array}{l}\text { "Evrikor - Forte + 7" } \\
1.51 / \text { ha }\end{array}$ & 76.8 & 23.2 & $114.6 \pm 4.3$ & $34.1 \pm 3.0$ & 189.3 \\
\hline & $\begin{array}{l}\text { "Evrikor - Forte + 7" } \\
2.51 / \text { ha }\end{array}$ & 69.6 & 30.4 & $119.0 \pm 3.9$ & $36.7 \pm 3.9$ & 203.7 \\
\hline & $\begin{array}{l}\text { "Evrikor - Forte + 7" } \\
3.51 / \text { ha }\end{array}$ & 79.0 & 21.0 & $111.0 \pm 2.7$ & $33.8 \pm 1.3$ & 187.6 \\
\hline $\mathrm{NSR}_{0.5}$ & - & - & - & - & 1.9 & 3.8 \\
\hline \multirow[t]{4}{*}{ YUzhnoural'skoe } & Without processing & 85.1 & 14.9 & $94.0 \pm 6.1$ & $23.9 \pm 0.9$ & 132.6 \\
\hline & $\begin{array}{l}\text { "Evrikor - Forte + 7" } \\
1.51 / \text { ha }\end{array}$ & 79.4 & 20.6 & $100.0 \pm 5.9$ & $27.1 \pm 1.9$ & 150.4 \\
\hline & $\begin{array}{l}\text { "Evrikor - Forte + 7" } \\
2.51 / \text { ha }\end{array}$ & 77.2 & 22.8 & $103.0 \pm 6.6$ & $29.2 \pm 2.7$ & 162.1 \\
\hline & $\begin{array}{l}\text { "Evrikor - Forte + 7" } \\
3.51 / \text { ha }\end{array}$ & 82.3 & 17.7 & $98.0 \pm 4.3$ & $25.6 \pm 1.7$ & 142.1 \\
\hline \multirow{4}{*}{$\begin{array}{l}\text { Orenburgskoe } \\
\text { pozdnee }\end{array}$} & Without processing & 82.9 & 17.1 & $140.0 \pm 4.4$ & $26.4 \pm 1.3$ & 146.5 \\
\hline & $\begin{array}{l}\text { "Evrikor - Forte + 7" } \\
1.51 / \text { ha }\end{array}$ & 76.8 & 23.2 & $153.0 \pm 5.2$ & $29.3 \pm 1.9$ & 162.6 \\
\hline & $\begin{array}{l}\text { "Evrikor - Forte + 7" } \\
2.51 / \text { ha }\end{array}$ & 75.4 & 24.6 & $158.0 \pm 4.9$ & $33.1 \pm 2.4$ & 183.7 \\
\hline & $\begin{array}{l}\text { "Evrikor - Forte + 7" } \\
3.51 / \text { ha }\end{array}$ & 80,7 & 19.3 & $150.0 \pm 8.4$ & $28.5 \pm 1.5$ & 158.2 \\
\hline \multirow[t]{4}{*}{ Zimnee } & Without processing & 84.2 & 15,8 & $120.0 \pm 4.9$ & $31.7 \pm 1.8$ & 162.7 \\
\hline & $\begin{array}{l}\text { "Evrikor - Forte + 7" } \\
1.51 / \text { ha }\end{array}$ & 73.4 & 26.6 & $125.1 \pm 5.6$ & $33.2 \pm 2.0$ & 183.9 \\
\hline & $\begin{array}{l}\text { "Evrikor - Forte + 7" } \\
2.51 / \text { ha }\end{array}$ & 70.1 & 29.9 & $132.1 \pm 4.7$ & $36.5 \pm 1.4$ & 202.2 \\
\hline & $\begin{array}{l}\text { "Evrikor - Forte + 7" } \\
3.51 / \text { ha }\end{array}$ & 77.5 & 22.5 & $123.4 \pm 3.5$ & $31.9 \pm 2.2$ & 176.7 \\
\hline $\mathrm{NSR}_{0.5}$ & - & - & - & - & 2.1 & 3.5 \\
\hline
\end{tabular}


Analyzing the results obtained, it was found that the drug "Evrikor - Forte +7 " had a positive effect on fruit trees, that is, the strength of fruit formation increased, the shedding of the ovary and fruits decreased.

According to Table 2, we see that the average fruit weight in summer varieties varied within $80.0-125.0 \mathrm{~g}$, and in winter varieties - within 94.0-158.0 g. The largest fruit weight was in the "Evrikor - Forte + 7" $2.51 /$ ha in varieties Orenburgskoe (129.0 g) and Orenburgskoe pozdnee $(158.0 \mathrm{~g})$, the indicator increased by 17.0 and $12.0 \%$, respectively, relative to the variant without treatment.

Of the studied variants of the experiment, "Evrikor Forte +7 " $3.51 /$ ha turned out to be less effective, an increase in fruit weight by an average of $7.0 \%$ was noted. The use of the drug "Evrikor - Forte +7 " had a positive effect on the increase in the average weight of apple fruits.

The yield of a variety is the most important indicator of its biological and economic characteristics and depends on ecological and agricultural practices in horticulture. By increasing the number of fruits and increasing the weight of each fruit, the yield of the studied variety increased.
The greatest increase in yield was obtained in the variant of the experiment "Evrikor - Forte + 7" 2.5 1/ha in the varieties Orenburgskoe pozdnee, Zimnee and YUzhnoural'skoe by $25.4 \%, 24.3 \%$ and $22.2 \%$, respectively. The smallest increase in yield was in the variant "Evrikor - Forte +7 " $-3.51 /$ ha in the Letnee polosatoe variety - by $3.0 \%$, in the YUzhnoural'skoe variety - by $7.2 \%$. Thus, the use of the biological product variant "Evrikor - Forte +7 " in apple trees promoted an increase in the productivity of trees and ensured a high yield per unit area.

Biochemical results showed that in the fruits of the studied varieties, the average dry matter content varied from $13.30 \%$ to $14.55 \%$. The highest dry matter content in the variant with the treatment "Evrikor - Forte +7 " at a dosage of $2.51 /$ ha was observed in the varieties Letnee polosatoe (14.53\%) and Orenburgskoe (14.55\%) (Table. 3). In the variant without treatment, this indicator turned out to be lower than that with the use of the drug in all studied varieties and varied from $13.30 \%$ (variety Orenburgskoe krasnoe) to $14.39 \%$ (variety Orenburgskoe).

Fruits were characterized by an increased sugar content $(>10 \%)$ in all variants of the experiment.

Table 03. Influence of the drug variant "Evrikor - Forte +7 " on the biochemical composition of fruits of summer and winter varieties of apple, 2018-2020

\begin{tabular}{|c|c|c|c|c|c|}
\hline Variety & Processing option & Vitamin C, mg / 100g & Sugar, $\%$ & $\begin{array}{l}\text { Soluble } \\
\text { dry matter, \% }\end{array}$ & Acids, $\%$ \\
\hline \multirow[t]{4}{*}{ Letnee polosatoe } & Without processing & $19.31 \pm 0.4$ & $10.60 \pm 0.2$ & $14.30 \pm 0.1$ & 0.70 \\
\hline & "Evrikor - Forte + 7" 1.51 / ha & $19.13 \pm 0.6$ & $10.53 \pm 0.4$ & $14.41 \pm 0.3$ & 0.68 \\
\hline & "Evrikor - Forte + 7" $2.51 /$ ha & $19.58 \pm 0.3$ & $10.61 \pm 0.2$ & $14.53 \pm 0.2$ & 0.66 \\
\hline & "Evrikor - Forte + 7" $3.51 /$ ha & $18.90 \pm 0.4$ & $10.50 \pm 0.3$ & $14.26 \pm 0.1$ & 0.70 \\
\hline \multirow[t]{4}{*}{ Orenburgskoe } & Without processing & $19.45 \pm 0.6$ & $10.66 \pm 0.2$ & $14.39 \pm 0.3$ & 0.68 \\
\hline & "Evrikor - Forte + 7" $1.51 /$ ha & $19.48 \pm 0.4$ & $10.62 \pm 0.3$ & $14.43 \pm 0.2$ & 0.69 \\
\hline & "Evrikor - Forte + 7" $2.51 /$ ha & $19.87 \pm 0.6$ & $10.64 \pm 0.3$ & $14.55 \pm 0.3$ & 0.66 \\
\hline & "Evrikor - Forte + 7" $3.51 /$ ha & $19.47 \pm 0.4$ & $10.55 \pm 0.2$ & $14.38 \pm 0.2$ & 0.70 \\
\hline \multirow[t]{4}{*}{ Orenburgskoe krasnoe } & Without processing & $15.40 \pm 0.4$ & $11.10 \pm 0.3$ & $13.30 \pm 0.3$ & 0.61 \\
\hline & "Evrikor - Forte + 7" 1.51 / ha & $15.45 \pm 0.3$ & $11.06 \pm 0.3$ & $13.34 \pm 0.2$ & 0.58 \\
\hline & "Evrikor - Forte + 7" $2.51 /$ ha & $15.51 \pm 0.4$ & $11.11 \pm 0.2$ & $13.42 \pm 0.3$ & 0.53 \\
\hline & "Evrikor - Forte + 7" $3.51 /$ ha & $15.42 \pm 0.2$ & $11.02 \pm 0.3$ & $13.32 \pm 0.3$ & 0.55 \\
\hline \multirow[t]{4}{*}{ YUzhnoural'skoe } & Without processing & $13.10 \pm 0.2$ & $9.84 \pm 0.2$ & $13.40 \pm 0.1$ & 0.71 \\
\hline & "Evrikor - Forte + 7" $1.51 /$ ha & $13.08 \pm 0.3$ & $9.80 \pm 0.2$ & $13.46 \pm 0.1$ & 0.76 \\
\hline & "Evrikor - Forte + 7" $2.51 /$ ha & $13.03 \pm 0.2$ & $10.02 \pm 0.2$ & $13.85 \pm 0.3$ & 0.83 \\
\hline & "Evrikor - Forte + 7" $3.51 /$ ha & $12.86 \pm 0.4$ & $9.83 \pm 0.2$ & $13.51 \pm 0.1$ & 0.79 \\
\hline \multirow[t]{4}{*}{ Orenburgskoe pozdnee } & Without processing & $16.33 \pm 0.4$ & $10.43 \pm 0.4$ & $13.84 \pm 0.3$ & 0.80 \\
\hline & "Evrikor - Forte + 7" $1.51 /$ ha & $15.71 \pm 0.2$ & $10.40 \pm 0.2$ & $13.31 \pm 0.1$ & 0.77 \\
\hline & "Evrikor - Forte + 7" $2.51 /$ ha & $15.89 \pm 0.2$ & $10.51 \pm 0.4$ & $13.79 \pm 0.1$ & 0.79 \\
\hline & "Evrikor - Forte +7 " $3.51 /$ ha & $15.60 \pm 0.3$ & $10.47 \pm 0.3$ & $13.71 \pm 0.3$ & 0.75 \\
\hline \multirow[t]{4}{*}{ Zimnee } & Without processing & $14.18 \pm 0.2$ & $10.29 \pm 0.3$ & $13.76 \pm 0.3$ & 0.83 \\
\hline & "Evrikor - Forte + 7" $1.51 /$ ha & $14.09 \pm 0.2$ & $10.31 \pm 0.1$ & $13.61 \pm 0.2$ & 0.79 \\
\hline & "Evrikor - Forte + 7" $2.51 /$ ha & $14.12 \pm 0.3$ & $10.13 \pm 0.3$ & $13.92 \pm 0.2$ & 0.73 \\
\hline & "Evrikor - Forte +7 " $3.51 /$ ha & $14.79 \pm 0.1$ & $10.02 \pm 0.2$ & $13.67 \pm 0.3$ & 0.77 \\
\hline
\end{tabular}

The general acidity gives the fruit a specific taste and, thus, contributes to their better assimilation. Organic acids in fruits using "Evrikor-Forte +7 " vary in the range from 0.53 to $0.83 \%$. The maximum indicator was obtained in the variant of the experiment "Evrikor - Forte + 7" $2.51 /$ ha in varieties YUzhnoural'skoe, Orenburgskoye pozdnee. The highest indicator of vitamin $\mathrm{C}$ was found in the variant
"Evrikor - Forte + 7" $2.51 /$ ha in the varieties Letnee polosatoe (19.52 mg / 100g) and Orenburgskoe (19.87 $\mathrm{mg} / 100 \mathrm{~g}$ ) and increased in comparison with the variant without processing by 1.4 and $2.1 \%$. 


\section{Conclusion}

1. As a result of the studies, the data obtained showed that the property of short stature as a genetic trait of resistance is transmitted to the offspring during hybridization. Trees are fast-growing, they begin bearing fruit in the third year. During reproduction, trees of natural dwarfs on seed vigorous rootstocks reach a height of $2.5 \ldots 3.0 \mathrm{~m}$.

2. The results obtained allow us to conclude that it is advisable to use the drug "Evrikor - Forte +7 " at a concentration of $2.51 /$ ha, which had a positive effect on fruit trees, that is, the strength of fruit formation, the percentage of useful ovary, fruit growth and strong retention on the tree were increased. All this contributed to an increase in the productivity of trees and ensured a high yield per unit area.

\section{References}

1. S. N. Khabarov Peculiarities of snow accumulation in the gardens of Siberia, Gardening of eastern Siberia (1980)

2. O. E. Merezhko, G. R. Mursalimova, S. E. Nigmatyanova, M. A. Tikhonova 2016 Modern gardening 4 (20) 11-18

3. E. N. Sedov 2015 Vavilov Journal of Genetics and Breeding 19 (1) 104-110

4. I. M. Shaitan 1983 Apple breeding in the SSR. pp. 107-111

5. I. M. Shaitan and T. P. Tereshchenko Using the Vydubetskaya Plakuchaya variety in the selection of new apple varieties with a low, leaderless crown ( Kiev, 1983)

6. O. E. Merezhko 2010 Materials of scientific and practical conference dedicated to the 75th anniversary of the founding of the Sverdlovsk selection station of gardening 46-49

7. P. Calvo, L. Nelson and J. W. Kloepper 2014 Plant Soil 383 3-41

8. P. Du Jardin 2015 Sci. Hort 196 3-14

9. M. Popko, I. Michalak, R. Wilk, M. Gramza, K. Chojnacka, H. Górecki 2018 Molecules 23 (2) 470

10. RSRISH 1995 Program and methods of breeding of fruit, small fruit and nutbearing crops (Orel) (In Russ.)

11. Ed G. A. Lobanov 1973 Program and methodology for the study of varieties of fruit, berry and nut crops (Michurinsk )

12. RSRISH 1999 Program and methodology for the variety study of fruit, berry and nut crops (Orel) 